or teaching paediatric ethics would be well advised to consider this book carefully.

DR PETER D TOON

General Practitioner 206 Queensbridge Road, London E8

\section{Reproductive Genetics and the Law} S Elias, G J Annas, 323 pages, Chicago, London, Boca Raton, £22.75, hbk, Year Book Medical Publishers Inc, 1987.

There is a rapidly increasing range of techniques for prenatal detection of genetic diseases and a rapid increase in the number of conditions which may be so detected. Similarly, therapeutic procedures of varying degrees of effectiveness and acceptability are continually being added to the medical repertoire. The methods of regulating reproduction by manipulating fertilisation and the early embryo are used to bypass human infertility and to make transgenic animals. All these technical developments have potential effects on human reproduction and development, make it possible to have choices with regard to particular genetic diseases or fetal damage and clearly have ethical and legal implications. Finally the number of drugs, industrial and agricultural products which may be teratogenic to the human fetus is also increasing beyond the capacity for testing. The rights and needs of society, the family, the mother, and the fetus differ, and may even be in apparent opposition, so that some basis for evaluation and decision is required.

Some knowledge of genetics and medical techniques is necessary for lawyers and legislators, and some knowledge of the law for genetic counsellors, researchers and scientists concerned with resource allocation. Professors Elias and Annas represent medical genetics and health law respectively, and their book offers a sustained and solid effort to appraise and educate. The book is enjoyably lucid throughout and covers a wide range of theoretical and technical matters. It deals with fundamental aspects of DNA structure and replication, meiosis, chromosomal behaviour and defects, genetic segregation, and the response to teratogens. It deals with screening, counselling, (and sensitivity to clients) prenatal diagnosis, embryo transfer perinatal surgery, and methods of inserting genes into eggs or cells. It also deals with legal problems involved in counselling, abortion and treatment; analysing and commenting on case law and on the problems involved and it discusses quality of life criteria, relative risks and conflict of rights.

It must seem ungrateful to wish that some problems which are touched upon too briefly or not at all had been discussed more fully. Since the main issues of the book all touch upon human need and human suffering and since the quality of life argument is an important part of the debate, (relevant to abortion versus treatment for example) then a better discussion of therapy would be in order.

Therapy is possible, in principle, for many metabolic diseases. It is less likely for those involving brain cells directly and seems unlikely for defects in structural proteins such as the collagen disorders.

Specific dietary restrictions are outlined briefly for three genetic conditions, and perinatal surgery for a few more. Nothing is said of unpleasant treatments which may prolong life for a time, but are palliative only; for example, weekly blood transfusions and daily injections of an iron-chelating agent for thalassemia. The quality of life is also affected by conditions which are not lethal for infants but which lead to severe pain such as sickle cell anaemia or Fabry's disease.

Changes to brain function may occur at teratogen levels too low to cause visible morphological change. A potentially normal fetus is irreversibly damaged in a phenotypically rescued mother homozygous for PKU, but the treatment they suggest is not properly tested and in any case prevention of microcephaly would not exclude possible deficits in intelligence and behaviour. With respect to industrial teratogens, exposure of a population may require wholesale offers of abortion to all pregnant women, as at Seveso.

More discussion on late onset genetic diseases would be valuable. An infant with Tay-Sachs will be soon dead, one with Duchenne muscular dystrophy will survive for several years, and Huntingdon's Chorea typically has a late onset. Arguments based on the number of valuable years of life must consider temporal gradations but the subjective experience of life before and during the degenerative period and the impact on the family also needs to be considered.

There is only a brief mention of resource allocation, yet decisions in this area may have an enormous effect on most of the issues discussed.

I hope that someone will write a book as clear and pleasant to read as this one, to illuminate English and Scottish laws, as this one has, for me, illuminated American law.

There is a reasonable index, a good list of chapter references and several useful tables.

R M CLAYTON Reader Department of Genetics University of Edinburgh West Mains $R d$ Edinburgh EH9 37N

\section{Saggi di Medicina e Scienze Umane}

(Published in Italian) E Mascitelli, A Ponsetto, N Luhmann, M G Lombardo, H J Helle, R Contardi, 339 pages, Milano, Lire 30,000, Istituto Scientifico S Raffaele di Milano, 1984.

The essays collected in this book were presented as lectures delivered at an experimental course held at the University Hospital S Raffaelle in Milano (Italy) in the academic year 1982-83. The aim of the course was to include some teaching of humanities in the curriculum of the Faculty of Medicine and this book is interesting as it represents a Catholic proposal to deal with this matter. Papers included are of different quality but all of them try to widen the horizon of medicine in the attempt to 'humanise' the general perspective. This approach is similar to the one advanced by E D Pellegrino and his group in the English-speaking world.

In this review, I shall focus my attention on N Luhmann's paper as it is the most interesting one and provides a good insight into the book's objectives.

According to Luhmann's systemic functionalism, society is an articulation of different partial systems. These partial systems are autonomous and independently developing. Medicine is one such partial system, with its own unique feature.

According to this view when a functional system has routine questions to answer the system is self-sufficient and can provide the decision using its own rules.

But when the (partial) system has to face exceptional questions then such 